\title{
Public exposure from I-131 hospitalized isolated patients in NIMRA Jamshoro Pakistan
}

\author{
Sajjad Ahmed Memon ${ }^{1}$, Naeem Ahmed Laghari ${ }^{1}$, Sadaf Tabasum Qureshi' ${ }^{2}$, Asrar Ahmad ${ }^{1}$, \\ Amin Ali Khan ${ }^{3}$, Muhammad Mubashar Hussain ${ }^{1}$ \\ ${ }^{I}$ Nuclear Institute of Medicine and Radiotherapy (NIMRA), Jamshoro, Pakistan. \\ ${ }^{2}$ Institute of Plant Sciences, University of Sindh, Jamshoro, Pakistan. \\ ${ }^{3}$ Institute of Radiotherapy and Nuclear Medicine (IRNUM), Peshawar, Pakistan.
}

Received February 14, 2014; Revised March 17, 2014; Accepted March 23, 2014; Published Online April 11, 2014

\section{Technical Report}

\begin{abstract}
Purpose/ Background: To treat the cancerous tissues the unsealed radioisotopes are being in clinical practice since 7 decades. From these unsealed sources, I-131 is the choice of treatment for the treating thyroid cancers. Orally administered I-131 patients are to be kept isolated in hospital for some period until captured activity in the body reaches to national and international limits for the avoidance of unacceptably high radiation exposures to patients' family members and the general public to keep ALARA (as low as reasonably achievable) principal in mind. The main rationale of this study was to calculate the exposure/dose of the general public. Material and Methods: This work presents the exposure rate and dose to the general public in the corridor and the non-radioactive patients admitted in adjacent room from I-131 administered isolated patients treated at NIMRA (Nuclear Institute of Medicine and Radiotherapy) Jamshoro Pakistan. In this study exposure from 23 thyroid cancer patients treated with different activities of I-131 (50 to $200 \mathrm{mCi}$ ) from January 2011 to December 2012 were included. Results: The average exposure rate in the corridor was about $5.17 \mu \mathrm{Sv} / \mathrm{hr}(2.14 \mu \mathrm{Sv} / \mathrm{hr}$ to $8.15 \mu \mathrm{Sv} / \mathrm{hr})$ and the cumulative dose to nonradioactive patients residing in an adjacent room was $0.647 \mathrm{mSv}(0.192 \mathrm{mSv}$ to $1.664 \mathrm{mSv})$. Conclusion: This study concludes that the exposure rate to the general public especially the admitted non-radioactive patient in the adjacent room is almost within the limits of $1 \mathrm{mSv}$ as specified in national and international standards.
\end{abstract}

Keywords: Unsealed Source; Isolation Room; ALARA; Radioiodine; Exposure Rate

\section{Introduction}

Radioiodine (I-131) is primarily $\beta$-emitting radionuclide with $610 \mathrm{keV}$ energy followed by a $364 \mathrm{keV}$ photon..$^{1-5} \beta$ ray emitted from radioiodine contributes the major radiation dose to the thyroid tissue and the gamma ray photon may give rise the potential radiation hazard to others. ${ }^{1,2}$ After first usage of I-131 by Saul Hertz and Arthur Roberts in January $1941^{6}$, it becomes an admired treatment option for patients with thyroid cancer. Obliviously the Patients administered I-131 therapeutic dosages are sources of undesir-

Corresponding author: Sajjad Ahmed Memon; Nuclear Institute of Medicine and Radiotherapy (NIMRA), Jamshoro, Pakistan.

Cite this article as:

Memon SA, Laghari NA, Qureshi ST, Ahmad A, Khan AA, Hussain MM. Public exposure from I-131 hospitalized isolated patients in NIMRA Jamshoro Pakistan. Int J Cancer Ther Oncol 2014; 2(2):020214. DOI: 10.14319/ijcto.0202.14 able high radiation exposure to close family members and the general public.

Usually the patients are to be hospitalized until the exposure rate from the patient's body surface at one meter falls to acceptable levels of $1 \mathrm{mSv}{ }^{7-9}$ according to national and international standard ${ }^{9-11}$ and ALARA principal. ${ }^{12}$ The main aim of this study was to record and calculate the exposure rate/dose to general public especially patients admitted in an adjacent room at Nuclear Institute of Medicine and Radiotherapy (NIMRA) Jamshoro Pakistan.

\section{Methods and Materials}

Exposure rate measurement is a key factor in radioiodine administered patients. The aim of the measurement of exposure rate is to maintain the radiation exposure/dose of the general public as low as reasonably achievable. ${ }^{12,13}$ If the administered activity to the patient is more than $30 \mathrm{mCi}$, 
hospitalization of patient is necessarily in a special isolation room is required until the achievement of captured activity to less than $30 \mathrm{mCi}$ or the drop off of exposure rate to less than $50 \mu \mathrm{Sv} /$ hour. ${ }^{12,} 14$ Twenty three radioiodine administered patients at NIMRA Jamshoro Pakistan with ages ranged from 17 to 68 years and administered I-131 activities ranged from $50 \mathrm{mCi}$ to $200 \mathrm{mCi}$ were included in this study. $\mathrm{Pa}$ tients' data such as age, sex, administered activity, date and time of administration were recorded. ${ }^{15-17}$ Initial exposure measurement for each of patient was recorded at the time of administration of activity with twice daily exposure rate measurement in corridor and adjacent room to isolation room were noted with calibrated LAMSE RM1001-RD survey meter (Figure 1). The procedure was briefed to the each patient and oral \& written instructions regarding isolation of patient were given to patient in order to keep the dose to family members and general public minimum. ${ }^{9}, 10,16,18-20,26$ The instructions were i) keeping the patient alone during hospital stay in a special isolated room; ii) allowing caregivers/family members to present meals and water to the patient for very short periods; iii) ensuring plenty of liquids intake; iv) chewing lemon/orange candies for minimizing salivary glands' dose; v) strongly advising lactating mothers to stop breast feeding to their babies immediately to prevent radioiodine ingestion through breast milk to the babies; vi) recommending pregnancy avoidance for a period of $4-6$ months after I-131 administration; vii) instructing the patients for maintaining safe distance between themselves and their family members \& general public, ensuring separate arrangements of sleeping, avoiding public transport travel and avoiding visit of public places such as shopping centers, restaurants, theatres \& public events; viii) for reduction of dose to caregivers/close family members, patients and their caregivers instructed for complying the same instructions at home after discharge from hospital for one to two weeks as maintained in isolation room.

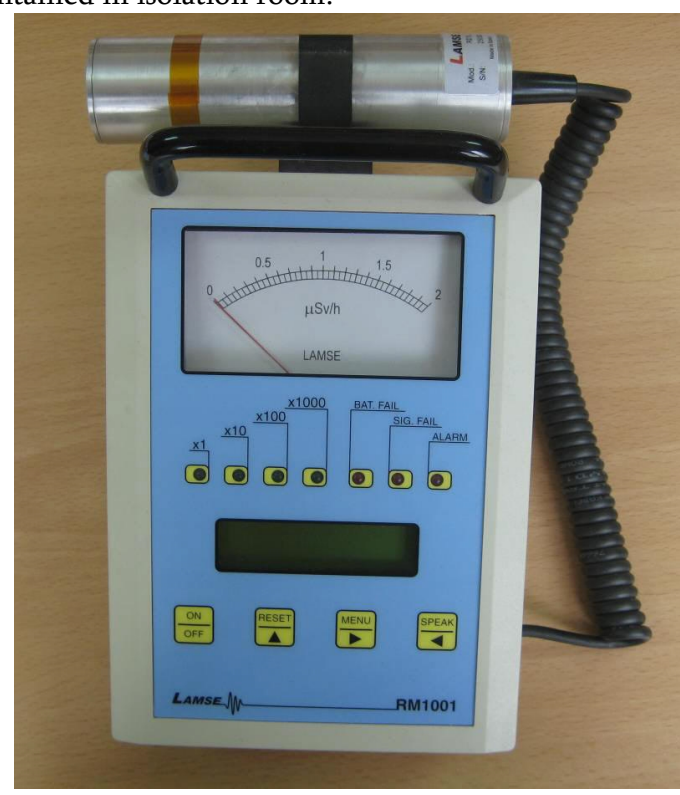

FIG. 1: LAMSE RM1001-RD survey meter.

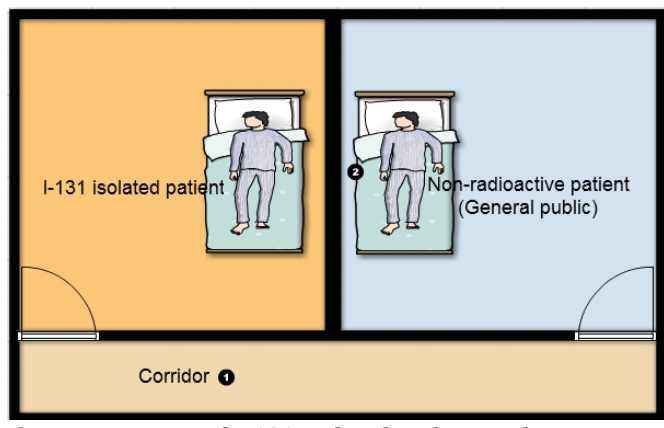

FIG. 2: Room setting of I-131 isolated and nonradioactive patients with points of exposure rate/ dose measurements.

Figure 2 shows the room setting of I-131 isolated and nonradioactive patients with points of exposure rate/dose measurements. It was ensured that no same patient in adjacent room received doses from the different patients. Every time of isolation of I-131 administered patients, different patient was admitted in adjacent room and there was no permanent occupancy in corridor as it was used as passage/pathway in the ward. The doses to nonradioactive patients in adjacent room were calculated from the readings of survey meter and the time duration of admission of I-131 isolated patients.

IAEA (International Atomic Energy Agency) mentioned in its documents ${ }^{21}$ that the majority of patients, excreted 50 $60 \%$ of the administered activity in the first 24 hours and different studies 2, $22-25$ revealed that the percentage of clearance of I-131 activity from patients is rapid (more than $80 \%$ ) in first 48 hours whereas Driver and Packer ${ }^{15}$ and Memon SA et al. ${ }^{26}$ reported that this clearance of magnitude of $(65-68) \%$. This indicated that the isolation period of isolated patients in ward is short so the public dose may be minor.

\section{Results}

The data of exposure rates in corridor and dose to patients admitted in adjacent room is presented in Table 1 . The recorded average exposure rates from isolated patients in corridor is ranged from $2.14 \mu \mathrm{Sv} / \mathrm{hr}$ to $8.15 \mu \mathrm{Sv} / \mathrm{hr}$ (average of $5.17 \mu \mathrm{Sv} / \mathrm{hr}$ ) and the cumulative doses to nonradioactive patients admitted adjacent room as indicated in Table 1 is ranges from $0.192 \mathrm{mSv}$ to $1.664 \mathrm{mSv}$ with an average of $0.647 \mathrm{mSv} .91 \%(\mathrm{n}=21)$ of patients in adjacent room received less dose than allowable limit of $1 \mathrm{mSv}{ }^{9-11}$ as shown in Figure 3. Only 2 (9\%) patients contribute some higher doses to non-radioactive patients admitted in adjacent room due to longer stay in isolation room than other patients.

The results of this study pointed out that the exposure to family members of patients and the general public can be minimized with i) sufficient radiation safety precautions and measurements. ii) abiding the instructions by I-131 administered patients. 


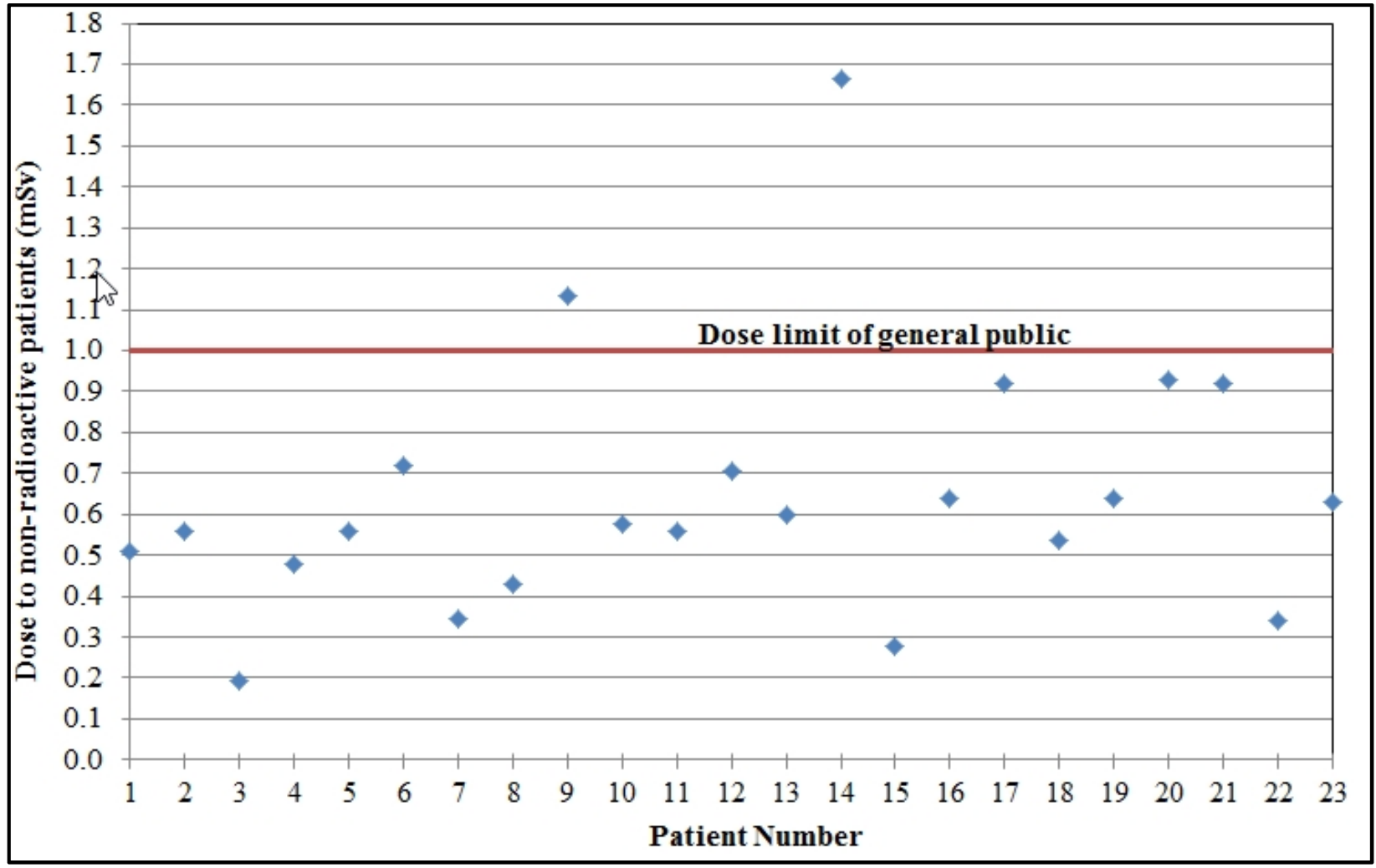

FIG. 3: Graphical representation of patient dose in adjacent room to I-131 isolated patient room with allowable limit (1 mSv) indication.

TABLE 1: Average exposure rate in corridor and dose in adjacent

\begin{tabular}{cccc} 
room. & & & \\
\hline \hline $\begin{array}{c}\text { Patient } \\
\#\end{array}$ & $\begin{array}{c}\text { Activity } \\
(\mathrm{mCi})\end{array}$ & $\begin{array}{c}\text { Average exposure rate } \\
\text { in Corridor }(\mu \mathrm{Sv} / \mathrm{hr})\end{array}$ & $\begin{array}{c}\text { Dose in adjacent } \\
\text { room }(\mathrm{mSv})\end{array}$ \\
\hline 1 & 85 & 4.000 & 0.512 \\
2 & 100 & 5.926 & 0.560 \\
3 & 50 & 2.222 & 0.192 \\
4 & 100 & 4.444 & 0.480 \\
5 & 120 & 5.185 & 0.560 \\
6 & 185 & 8.148 & 0.720 \\
7 & 155 & 4.000 & 0.344 \\
8 & 105 & 3.844 & 0.429 \\
9 & 145 & 6.994 & 1.133 \\
10 & 150 & 6.889 & 0.576 \\
11 & 90 & 5.185 & 0.560 \\
12 & 175 & 7.556 & 0.704 \\
13 & 100 & 5.556 & 0.600 \\
14 & 150 & 4.667 & 1.664 \\
15 & 95 & 3.333 & 0.280 \\
16 & 100 & 6.667 & 0.640 \\
17 & 150 & 3.889 & 0.920 \\
18 & 100 & 6.778 & 0.536 \\
19 & 150 & 7.778 & 0.640 \\
20 & 200 & 5.000 & 0.930 \\
21 & 150 & 5.772 & 0.919 \\
22 & 160 & 2.135 & 0.341 \\
23 & 100 & 2.828 & 0.632 \\
\hline \hline
\end{tabular}

\section{Discussion}

Along with family members/caregivers, the general public/non-radioactive patient admitted in adjacent room are also at risk from I-131 administered patients isolated in ward but through proper radiation protection measurements it can be effectively managed. ${ }^{27}$ The exposure rate/dose of the general public from patients administered with I-131 during stay at hospital needs some considerations. The comparison of current study is not possible due to non-availability of data on this study topic.

Although many studies $14,17,26,28-34$ have been conducted on the dose to caregivers/family members of the patients as summarized in Table 2 but no data was found for exposure rate/dose to the general public from the I-131 therapeutic patients. As Table 2 showed that the doses to caregivers/family members of the patients are within acceptable limits, which pointed out that the dose to the general public, will also be in the allowable limits and the patients treated with radioiodine do not contribute a significant radiation dose to the public. ${ }^{35}$ 
TABLE 2: Different studies for dose to caregivers/family members of I-131 administered patients.

\begin{tabular}{lc}
\hline \hline Study & $\begin{array}{c}\text { Dose to caregivers/family members } \\
\text { (mSv) }\end{array}$ \\
\hline Grigsby et al. ${ }^{14}$ & 0.01 to 1.09 \\
Willegaignon et al. ${ }^{17}$ & $<1$ \\
Memon et al. ${ }^{26}$ & 0.0321 to 0.235 \\
AlMaskery and Bererhi ${ }^{28}$ & $<1$ \\
Rutar et al. ${ }^{29}$ & 0.17 to 4.09 \\
Tonnonchiang et al. ${ }^{30}$ & $<1$ \\
Marriott et al. ${ }^{31}$ & 0.283 \\
Sapienza MT et al. ${ }^{32}$ & $<1$ \\
Reiners and Lasmann ${ }^{33}$ & $<1$ \\
Cappelen et al. ${ }^{34}$ & $<1$ \\
\hline \hline
\end{tabular}

The studies done by Thompson MA 2, Driver and Packer ${ }^{15}$, IAEA 21, Pacilio et al. ${ }^{22}$, Tavakoli ${ }^{23}$, Parthasarathy and Crawford ${ }^{24}$, Tuntawiroon et al. ${ }^{25}$, and Memon SA et al. ${ }^{26}$ reported that the most of activity cleared from patient in first 24 hours which confirmed that the public dose will not be significant due to short isolation period of patients in ward.

Due to deficiency in research on the current topic, the comparison is impossible but the studies ${ }^{2,15,21-26}$ vigorously supported the result of the current study.

\section{Conclusion}

The current study indicates that the exposure rate in corridor is within acceptable limits and most of data for dose to non-radioactive patients in adjacent room is also within tolerable limits. As there is no previous data available due to lack of research on the current topic so authors suggest that more studies may be conducted on subject to compare the dose to the general public and for the authentication of current study.

\section{Acknowledgements}

The authors would like to thank Mr. Khalid Hussain, Hot Lab technician, the ward staff for their help and assistance, without their cooperation, this study could not be completed successfully.

\section{Conflict of interest}

The authors declare that they have no conflicts of interest. The authors alone are responsible for the content and writing of the paper.

\section{References}

1. Hamizah NMZ, Juliana MR, Waidi AI, et al. Surface contamination in skin and room during hospitalization of thyroid cancer patient receiving radioiodine ablation. Journal of Dental and Medical Sciences 2012; 2:27-33.

2. Thompson MA. Radiation safety precautions in the management of the hospitalized (131)I therapy patient. J Nucl Med Technol 2001; 29:61-6.

3. Muhammad W, Faaruq S, Hussain A, et al. Quantitative analysis of the factors responsible for over or under dose of 131 I therapy patients of hyperthyroidism. Radiat Prot Dosimetry 2008; 128:90-7.

4. Meier DA, Brill DR, Becker DV, et, al. Procedure guideline for therapy of thyroid disease with (131)iodine. J Nucl Med 2002; 43:856-61.

5. Thomas SR. Options for radionuclide therapy: from fixed activity to patient-specific treatment planning. Cancer Biother Radiopharm 2002; 17:71-82.

6. Chow SM. Side effects of high-dose radioactive iodine for ablation or treatment of differentiated thyroid carcinoma. J Hk Coll Radiol 2005; 8:127-35.

7. International Atomic Energy Agency (IAEA). Therapeutic nuclear medicine General overview IAEA web page on radiological protection of patient. Available from https://rpop.iaea.org/RPOP/RPoP/Content/Informa tion-

For/HealthProfessionals/3_NuclearMedicine/Thera peuticNuclearMedi-

cine/Therapeutic_nuclear_medicine_-_general_ove rview.htm

8. European Commission. Radiation Protection 97. Radiation protection following Iodine131 therapy (Exposure due to outpatient or discharged inpatients). Directorate General of Environmental Nuclear Safety and Civil Protection Luxembourg, Brussels 1998.

9. Pakistan Nuclear Regulatory Authority (PNRA). Regulations on radiation protection (PAK/904) 2004.

10. Venencia CD, Germanier AG, Bustos SR, et al. Hospital discharge of patients with thyroid carcinoma treated with ${ }^{131} \mathrm{I}$. J Nucl Med 2002; 43:61-5.

11. International Atomic Energy Agency (IAEA). Safety standards series no. RSG1.7: Application of the concepts of exclusion, exemption and clearance. Vienna, Austria. 2004.

12. International Commission on Radiological Protection (ICRP). ICRP Publication 103: The 2007 Recommendations of the International Commission on Radiological Protection. Editor J. Valentin, Elesevier Oxford, UK. March 2007. 
13. Willegaignon J, Guimaraes MI, Sapienza MT, et al. A new proposal for monitoring patients in nuclear medicine. Health Phys 2006; 91:624-9.

14. Grigsby PW, Siegel BA, Baker S, Eichling JO. Radiation exposure from outpatient radioactive iodine $\left.{ }^{131} \mathrm{I}\right)$ therapy for thyroid carcinoma. JAMA 2000; 283:2272-4.

15. Driver I, Packer S. Radioactive waste discharge quantities for patients undergoing radioactive iodine therapy for thyroid carcinoma. Nucl Med Commun 2001; 22:1129-32.

16. Al-Haj AN, Lagarde CS, Lobriguito AM. Patient parameters and other radiation safety issues in ${ }^{131} \mathrm{I}$ therapy for thyroid cancer treatment. Health Phys 2007; 93:656-66.

17. Willegaignon J, Sapienza M, Ono C et al. Outpatient radioiodine therapy for thyroid cancer: a safe nuclear medicine procedure. Clin Nucl Med 2011; 36:440-5.

18. Sabih D. Treatment of thyrotoxicosis with radioactive iodine. Recommendations of the consensus group on nuclear medicine protocols (Pakistan). World J Nucl Med 2006; 5:21-47.

19. Recommendation for the discharge of patients undergoing treatment with radioactive substances. Australian Radiation Protection and Nuclear Safety Agency (ARPNSA) Radiation protection series no. 4, 2002.

20. US Nuclear Regulatory Commission. Regulatory analysis on criteria for the release of patients administered radioactive materials (NUREG1492). 1997.

21. International Atomic Energy Agency (IAEA). Nuclear medicine in thyroid cancer management: a practical approach, IAEA-TECDOC-1608. Vienna, Austria. 2009.

22. Pacilio M, Bianciardi L, Panichelli V, et al. Management of ${ }^{131} \mathrm{I}$ therapy for thyroid cancer: cumulative dose from in-patients, discharge planning and personnel requirements. Nucl Med Commun 2005; 26:623-31.

23. Tavakoli MB. Radioactive discharge from patients with thyroid cancer under ${ }^{131} \mathrm{I}$ treatment and its safe disposal to the public sewer system. Contemp Oncol 2005; 9:38-41.

24. Parthasarathy KL, Crawford ES. Treatment of thyroid carcinoma: emphasis on highdose ${ }^{131} \mathrm{I}$ outpatient therapy. J Nucl Med Technol 2002; 30:165-71.
25. Tuntawiroon M, Sritongkul N, Pusuwan $\mathrm{P}$, et al. Radiation exposure from liquid discharges from ${ }^{131} \mathrm{I}$ therapy rooms into the piping system of a hospital building. In vivo therapeutics: World J Nucl Med 2008; 7:122-5.

26. Memon SA, Laghari NA, Qureshi ST, et al. Exposure rate patterns in ${ }^{131} \mathrm{I}$ therapy inpatients at NIMRA Jamshoro: an 08year study. PJNM 2013; 3:29-36.

27. International Atomic Energy Agency (IAEA). Safety reports series no. 63: Release of patients after radionuclide therapy. Vienna, Austria. 2009.

28. AlMaskery I, Bererhi H. Radiation exposure levels in family members of Omani patients with thyrotoxicosis treated with radioiodine $\left({ }^{131} \mathrm{I}\right)$ as outpatients. SQU Med 2009; 9:148-52.

29. Rutar FJ, Augustine SC, Colcher D, et al. Outpatient treatment with $\left({ }^{131} \mathrm{I}\right)$-anti-B1 antibody: Radiation exposure to family members. J Nucl Med 2001; 42:907-15.

30. Tonnonchiang S, Sritongkul N, Chaudakshetrin P, Tuntawirron M. Radiation exposure to relatives of patients treated with iodine-131 for thyroid cancer at Siriraj hospital. Available from: www.Tmps.Or.Th/Meeting2012/Fullpaper/Siriporn .Pdf

31. Marriott CJ, Webber CE, Gulenchyn KY. Radiation exposure for 'caregivers' during high-dose outpatient radioiodine therapy. Radiat Prot Dosimetry 2007; 123:62-7.

32. Sapienza MT, Willegaignon J, Ono CR, et al. Radioiodine therapy of differentiated thyroid cancer: radiologic impact of out-patient treatment with 100 to $150 \mathrm{mCi}$ Iodine-131 activities. Arq Bras Endocrinol Metabol 2009; 53:318-25.

33. Reiners C, Lasmann M. Radioiodine (131I) treatment of hyperthyroidism: radiation protection and quality assurance. Eur J Nucl Med 1999; 26:683-5.

34. Cappelen T, Unhjem JF, Amundsen AL, et al. Radiation exposure to family members of patients with thyrotoxicosis treated with iodine-131. Eur J Nucl Med Mol Imaging 2006; 33:81-6.

35. Sulaiman BT, Clarke SE. Radiation doses to patient's relatives following radioiodine therapy. Med J Malaysia 1996; 51:131-3. 